\title{
Analysis Of The Variables Of Intention Of The Adoption And Acceptance Of Artificial Intelligence And Big Data Tools Among Leaders Of Organizations In Morocco: Attempt Of A Theoretical Study
}

\author{
Moudni Yousra (PhD Student) \\ Chafik Khalid (Teacher-Researcher) \\ Management \& Information Systems Research Team \\ ENCG of Tangier, Abdelmalek Essaadi University, Morocco
}

Doi:10.19044/esj.2021.v17n29p106

Submitted: 21 January 2021

Accepted: 20 July 2021

Published: 31 August 2021
Copyright 2021 Author(s)

Under Creative Commons BY-NC-ND 4.0 OPEN ACCESS

Cite As:

Yousra M \& Khalid C. (2021). Analysis Of The Variables Of Intention Of The Adoption And Acceptance Of Artificial Intelligence And Big Data Tools Among Leaders Of Organizations In Morocco: Attempt Of A Theoretical Study. European Scientific Journal, ESJ, 17(29), 106. https://doi.org/10.19044/esj.2021.v17n29p106

\section{Abstract}

Artificial intelligence and big data are two emerging technologies that is now gaining ground among organizations. Their added value and their impact on business performance differ from one industry to another. Due to increased competitiveness, and in order to survive in the market, companies are led to adopt these new technologies that will enable them to be more performant and offer customers goods or services that meet their real needs since this approach is based on data collected from outside the company's environment. To do so, it is important to know and analyze beforehand the factors and variables that impact the adoption and acceptance process in order to manage them. This paper focuses on establishing a synthetic literature review to find out the current state of researches on the problems of AI and Big data adoption and acceptance, and it also argument the empirical sector's choice. The findings of this study show that agricultural and chemical industry sectors are the two most promising sectors for AI in Morocco. As a result, a comparative analysis will be conducted after the development of the research model on these two fields in order to analyze the variables of adoption and acceptance of AI. Also, the most influential variables according to the 
literature were detected in this paper, which are grouped into four (4) types: technological, organizational, environmental, and behavioral variables.

Keywords: Artificial Intelligence, Big Data, Organizations, Adoption, Acceptance, Variables, Frameworks

\section{Introduction}

In 1956, the advent of artificial intelligence named by McCarthy sparked the design of systems to model the complexity of human intelligence. Researchers designed these systems as brains isolated from a body, excluding action in the development of their knowledge. Achievements seemed to prove, through their efficiency, that computers do not need sensory and motor organs to reason or communicate.

Since then, a lot of researches have been carried out and criticisms have been exposed by philosophers and researchers. Nonetheless, this has not limited the willingness to exploit the possibility of this technological revolution. Until 2010, questions have not ceased on the ethics of AI integration in many sectors. However, with the emergence of Big Data, data became so voluminous that it exceeded intuition and human analytical capabilities, and even the capacities of conventional computer tools for database or information management. It is from this moment that some companies took the lead on the world stage to implement AI as a way to understand and analyze data and obtain accurate information in real time.

Morocco, a developing African country, started its digital transition recently, and it currently ranks 4th in the Middle East and North Africa region in terms of digital competitiveness. Its main goal is to become a digital and technological hub of reference at the African level. Therefore, it has started in parallel with the data engineering phase which consists of collecting, digitizing, and facilitating access to data and then analyzing them. In addition, it has allocated a budget of 57M dollars in 2019 to cover 7 transactions related to $\mathrm{AI}$, and 50M MAD to fund research projects related to this new technology in 11 different areas. Admittedly, the perspective of AI is positive, but Morocco is still ranked second to the last in the Middle East Africa region in terms of AI. This has posed various questions regarding the source of the issue. To understand this phenomenon, artificial intelligence is understood from its socio-technical and behavioral aspects through its emergence, importance, acceptance, and adoption by companies. This technology was studied from the behavioral and sociotechnical school because it looks at technologies in their management aspect, yet it does not completely dissociate itself from the technological academy.

The aim of this paper is to define the research problem which is the analysis of the variables of the intention to adopt and accept artificial 
intelligence and big data tools among the leaders of organizations in Morocco. In order to do so, the emergence of Artificial Intelligence is considered. Thereafter, the two technologies were defined and their importance to companies were highlighted. After then, the literature to explore the progress of researches in this field were reviewed and the variables that may constitute the future research model was also defined. Also, the choice of empirical sector was justified and, before concluding this paper, the results was synthesized and a central research question and sub-questions were also formulated.

The benefits of this paper are to have a clear idea of the research topic, to find out what are the most influential variables and models used to analyze the adoption and acceptance of AI, and finally to determine the empirical research field so as to test the future model. If this study was not conducted, it will be difficult to see clearly the reality of each sector and there would be a high risk of conducting a study on an environment that is not fertile for AI. Thus, this will bias the results or block the study due to lack of information.

\section{Previous Research Works}

Empirical investigations and theoretical developments in AI's business application are quite restricted compared to the total number of researches conducted within this technology. The connection, collaboration, and communication between man and machine, innovative business models and ecosystems, labor market perturbations, and the creation of added value in the different sectors are the major axes dealt with during academic studies on AI application. Regarding the understanding of the use of this technology and the impact of AI's adoption on organizational and individual aspects, few academic studies with rigorous scientific research or theories exist.

Based on the aspect of adoption by companies, researchers have emphasized the importance of both innovative employee roles and working relationships between humans and machines. However, there is a noticeable gap of knowledge concerning the variables that impact the adoption and acceptance of this technology on an individual and organizational aspect. Indeed, by examining in more detail the way in which AI is adopted and the variables that will impact its acceptance by users, different public and private organizations can gain a better understanding of the phenomenon. Also, they will be able to react positively to the variables, which will allow them to adapt it easily and make more investments on this new concept.

The studies done so far have touched the acceptance of specific tools of AI such as self-driving cars, chatbots and robo-advisors, wearable payment and so on. In addition, the sectors where the studies on AI are made are especially education and higher education through e-learning, health and finance sector, media and telecom industry, and service deliveries. It appears 
that this area of research lacks knowledge, particularly for Morocco, where the total number of published articles is about 730 . Out of the 730 published articles, only 30 are related to business and management but are without relevance to the analysis of acceptance or adoption's variables. This, therefore, results to the origin of the research problem which is the analysis of the variables of the intention of adopting AI and Big data tools among the leaders of the organizations in Morocco.

According to Mahroof (2018), the theoretical model that the researchers must use in their investigation to understand this complex phenomenon should combine several models that exist in the literature and which aim to study the adoption of information technologies such as: Technology Acceptance Model, Unified Theory of Acceptance and Use of Technology, Technology Readiness Theory, Social Cognitive Theory, etc. The model used should be specific for each sector and each aspect of AI. Also, these models must include factors that are born with AI which are data and trust.

Three types of variables are distinguished in information systems research: technological, organizational, and behavioral. Technological variables include both internal and external technologies that cover equipment and processes. Organizational variables refer to the managerial / structural characteristics and resources of a company. Behavioral factors are the ones which stem from human behavior towards something. Thus, the literature shows the variables mostly used in the models of adoption and acceptance of artificial intelligence tools which constitutes the search model.

\section{Artificial Intelligence and Big Data: Complex Phenomena The History of Artificial Intelligence's Emergence}

The world has experienced four (4) great industrial revolutions all through the years. The first was in 1784 known as mechanization, which is characterized by the invention of the hydraulic machine, the steam engine, and mechanical production. This was followed by electrification in 1870 encompassing mass production and division of labor as well as the use of electrical energy. Automated production using electronics has led to automation in 1969 due to technology and information technology. This resulted to digitization introduced by the virtualization and interconnection of intelligent industrial objects in 2011.

This latest revolution came about as a result of successive years of inventions and innovations. It started with binary logic until it arrives at digital transformation using SMAC (Social, Mobile, Analytics and Cloud) and DARQ technologies (Distributed ledger, Artificial intelligence, Extended reality and Quantum calculation). 
In fact, it was between the First and Second World Wars that binary logic was developed on the basis of Boole's work. The latter allowed the creation of the first fully electronic computer (ENIAC) in 1945 succeeded by several inventions. Finally, the IBM Company launched the first computer for sale in 1959.

In the meantime, artificial intelligence had already emerged at a conference at Dartmouth College in 1956 aiming to create computers as intelligent as humans. Between the 1960s and 1995, AI went through two important phases: the golden age during which a large number of algorithms were found, and the AI winter when investments declined due to the lack of general intelligence. Consequently, in May 1997, an event marked the world of AI which was the deep blue computer that defeated the champion, Garry Kasparov, in the game of chess. However, this did not translate into a definition of general intelligence that will answer all problems. Nevertheless, the arrival of big data tipped the balance in favor of AI.

The term "Big Data" is not recent but appeared in 1997 in a scientific article on the technological challenges for visualizing large datasets. Yet it only became globally known in 2010 when the boss of Google said that his company produces every two days as much information as they had generated since the dawn of civilization until 2003. This explosion in the volume of data is the main consequence of the combination of several factors, namely:

- The launch of 3G in 2001 allowing users mobile and fixed wireless internet access, video calls and mobile TV and the introduction of $4 \mathrm{G}$ in the early 2010's which enabled more advanced services such as 3D TV and video conferencing;

- The growth of the leading companies of the web such as Google, Facebook, LinkedIn, Amazon and Twitter in 2005;

- Information sharing via social networks and internet geolocation;

- The expansion of the Cloud providing access to IT services online; and

- The Internet of Things that ensures the communication between physical goods and their digital existence.

Indeed, there have been a multitude of sources that have promoted the increase of data like sensors, web, after-sales services, etc. So, to handle and analyze this huge volume of data, several technologies have emerged and have shown their effectiveness, especially artificial intelligence tools such as machine learning and deep learning.

\section{Big Data Approach}

Big data refers to voluminous and varied data collected from various digital tools, and whose processing requires complex platforms and tools. The Big Data is often described by its 3Vs: Volume, Velocity and Veracity, and it can be structured, unstructured or semi-structured. Other researchers such as 
Demchenko et al. (2013) and Saggi and Jain (2018) mentioned respectively 5V's and 7 V's, adding to the literature 4 new characteristics that are variety, value, valence, and variability. The storage of this huge quantity of information cannot be done through traditional data storage, and its analysis seems impossible with conventional data analytics or business intelligence technologies. Hence, it needs new advanced technologies like those offered by artificial intelligence tools.

In business, big data is considered as a new approach that allows organization to analyze a large amount of information so as to help managers take better decisions and satisfy the costumer while being efficient and effective. The new vision of organizations is based on client satisfaction. Therefore, using this approach will be useful to understand their reaction to products/services by collecting and analyzing the various information posted on different digital platforms. In addition, big data can be the best way to benchmark companies and optimize internal and external processes.

\section{Artificial Intelligence Approach and Tendencies}

The first use of artificial intelligence was in 1956 at a seminar held at Dartmouth College. The term "artificial intelligence" is used to refer to the part of computer science whose tools renounce algorithmic constructions and analytical data processing in favour of heuristics and a global approach. Hence, AI is also known as cognitive technology.

A machine is considered to be intelligent from the moment when its functioning has the appearance of that of the human intellect. Artificial intelligence is actually characterized by the ability to learn from data sets and tasks, instead of pursuing and running a set of pre-established procedures and rules, and to continually adapt its behaviors to optimize results. AI's interest also entails the development of a set of skills for companies instead of providing a specific tool or technology. It combines several technologies that can accomplish and/or enhance the actions, analysis, interventions, and decision-making that rely on human intelligence.

Confronted with AI, companies are facing the same type of challenge just like when computers or information technology were introduced, which is a structural and organizational challenge. However, they cannot prevent AI's risks through an approach tested and validated because of the rapid growth of the technology and the transformative effect of its utilities. To remain competitive in the market, they have to integrate it in order to support existing services and strengthen research and development within their structure. 


\section{Theoretical Frameworks}

This work complements a series of studies carried out within the ENCGT's Management and Information Systems research team that aim to analyze the variables of adoption and acceptance of different technologies within organizations, namely: the intention of the adoption of e-commerce among the leaders of Moroccan SMEs, the adoption of ERPs in large Moroccan public enterprises, and the acceptance of audit automation software used by financial auditors on legal mission. These technologies are studied from the sociotechnical and behavioral school perspective which considers both management standpoint and technological characteristics. The research will proceed along the same path. Thus, artificial intelligence and big data will be treated from the same context. To do so, the sequence of steps shown in the following figure is followed:

Phase 1: Conduct a search through Scopus, Web of Science and Google Scholar databases for articles published between 2015 and 2021 concerning the adoption or acceptance of AI tools in different sectors and countries.

Phase 2: Filter the articles to keep only those treating the subject from a variable point of view, i.e. analyzing variables influencing the process.

Phase 3: Read and synthesize the articles, then identify the most important variables for each study and the basic model used to construct the theoretical model used.

Phase 4: Regroup the repeating variables and prepare our synthetic review.

Figure 1. The phases of the framework

\section{Frameworks Used and Variables Detected}

Chen (2019) analyzes in his article the organizational factors that impact the adoption of AI in the telecom industry in China using the TOE framework. Based on his study, the technical skills, i.e., the support and knowledge needed to implement a new technology within organizations, are not related to the adoption of AI, but he mentions its potential role in other industries. On the other hand, Pillai et al. (2020) found that organizational readiness, i.e., availability of budget, resources and skills, is very important for both adoption and acceptance of technology by employees. Also, Lee et al. (2020), who based their research model on the MTAM model, fashion theory and technology readiness theory, consider the variable "technology readiness" as a significant input of their model because it is proved that it has a positive influence on the usefulness and ease of use of the wearable payment. Thus, this is a tool that is implemented with deep learning which is a form of artificial 
intelligence. In addition, Ye et al. (2019) found that perceived behavioral control which also means availability of skills, resources, and opportunities to use AI is a significant variable and has influence on perceived ease of use and perceived usefulness using the TAM model.

Security and privacy concerns is considered as an initial determinant variable when analyzing the intention to adopt AI by several authors, namely: Pillai et al. (2020), Ye et al. (2019), and Alsheiabni et al. (2019). According to them, if there are issues, it will negatively influence the process of adoption and use in automated retail stores, health care sector, and organizational level in general.

According to Ullah et al. (2018) who studied AI adoption in real estate sector and Shibly (2020) who conducted a study on business intelligence adoption, the quality of the information results of the program used is very important in the choice of adoption. This is because if the output is not of good quality, it will negatively impact the quality of the decision taken and, consequently, the satisfaction of stakeholders and the benefits of the organization. Both authors based their research on TAM model as a basic one but Alshibly added the D\&M model to support his analysis.

Task complexity plays a crucial role in AI adoption because according to Fan et al. (2020), it influences performance expectancy and effort expectancy for using AI tools and, consequently, the behavior of adopting changes.

Cost effectiveness, which means the net incomes from an investment, is a variable that was studied by both Adnan et al. (2018) and Pillai et al. (2020) while analyzing autonomous vehicle acceptance and AI adoption in the recruitment process of IT organizations. Both of them agree that it negatively affects the process because investors seek to benefit from each move they attempt to do. Other authors analyzed the cost variable from other perspectives. Chen (2019) called it industry investment means whether the sector is willing to invest in these technologies considering their frequent disruption or not. Alsheiabni et al. (2019) named it funding availability in the organization that he considered a low impact variable on adoption at organizational level. Instead, top management support remains critical in the latest three researches and it can form a barrier towards adoption. From this, other factors that may delay the adoption and acceptance phase can be put into consideration. This includes employee resistance to change as noted by CruzBenito et al. (2019) and Ye et al. (2019) when analyzing the acceptance of AI in e-learning and health care sector. Furthermore, there is perceived substitution crisis named by Fan et al. (2020) who used UTAUT model to analyze the adoption of AI-based medical diagnosis support system. As stated in their article, the fear of being replaced by machines pressures the employees. 
Kencebay (2019) showed in her study that robots and driverless car's awareness are two factors that have a significant effect on the acceptance of these two technologies through their impact on the perceived enjoyment of the individual. Since the two innovations use AI to operate, and the study will focus on the adoption of AI tools in organizations, awareness can be considered as a variable that may be used in the model.

Kim and Kim (2020) identified in their paper the factors that mostly impact the adoption of AI-generated press articles. Trust in technology was among the variables they were able to detect. According to their study, trust in technology strongly impacts the decision to accept or not accept the product. Hence, this can be considered as a behavioral variable. The same variable is used in the model of Du et al. (2021) and it proves again its significant importance in the acceptance of self-driven cars. Same results appear in the study of Fernandes and Oliveira (2021) who based their research framework on sRAM model to understand the driver's acceptance of the adoption of digital voice assistants.

The variable subjective norms, which are related to personal beliefs, is a variable that comes up repeatedly in the research studies. Fernandes and Oliveira (2021), Du et al. (2021), Ye et al. (2019), and Belanche et al. (2019) have approved its direct or indirect effect during their surveys.

Last but not least, external environment has a considerable impact and influence on this process. According to Pillai and Sivathanu (2020) and Chen (2019), competitive pressure should be considered as a variable in the choice of implementing AI tools or not. As competitiveness increases, companies are forced to look for ways to gain a competitive advantage. In Chen's study, it didn't have much influence because of the Chinese market's characteristics. He also added the variables AI vendor partnership and government involvement in stimulating AI innovation to his model and he found that the hypothesis of influencing AI adoption is supported and are very critical.

\section{Digital Transformation as One of the Intermediate Variables of the Model}

To better explain the evolution and trend of Artificial Intelligence, the literature considers the variable of digital transformation. Dejoux (2018) describes digital transformation as an important and transitional step for organizations that aims to prepare entities for the next phase of AI that will replace and/or assist collaborators in the realization of many tasks with low added value for humans. In order to implement this new technology, the concerned entities must have agile and digitized processes and a data culture. As a result, employees will be prepared to use AI systems, empowering them with quality data, and educating, controlling, developing and linking them to human tasks to create new sources of added value. Henriette et al. (2016) consider that, as a result of digital transformations and developments, 
organizations are forced to implement big data models within their structures, thus creating new business lines in relation to this new technology. However, Kazakçi (2017) links the wave of big data to digital transformation and considers that it can be done through data and AI. Therefore, the digital transformation can be considered as a technological variable of the predictive model for the adoption of artificial intelligence and big data tools.

Consequently, the digital transformation is a deep transformation of the organization that allows an impact on its performance in a sustainable way. Thus, it is carried out at different levels:

- Digitalization of operations / processes through the adoption of digital solutions for the field teams, which will make the processes more fluid and agile. It also tries to dematerialize as much as possible every material and make it electronic.

- Digitizing the organization by implementing digital innovation, having connected teams who collaborate digitally with each other, etc.

- Digitalization of the citizen experience through digital marketing, ecommerce, digital services, etc.

- Digitalization of products and services by conceptualizing a new digital business model, digitizing customer support through chatbots to answer customers $24 / 7$, setting up digital R\&D, etc.

Different technologies fall within the scope of digital transformation and can be divided into four categories:

- Communication, data capture, and centralization technologies such as cloud, mobile, IoT, geolocation and social networks;

- Analysis and intelligence technologies such as big data, analytics and AI;

- Technologies of increased capabilities such as robotics, 3D printing, drones and virtual and augmented reality;

- Security technologies such as blockchain and biometrics.

In summary, there are four (4) variables of this study that can be included in the research model as shown in Table 1 below:

Table 1. Variables that might impact AI adoption and acceptance

\begin{tabular}{|c|c|c|c|}
\hline Technological Variables & $\begin{array}{c}\text { Organizational } \\
\text { Variables }\end{array}$ & $\begin{array}{c}\text { Environmental } \\
\text { Variables }\end{array}$ & $\begin{array}{c}\text { Behavioral } \\
\text { Variables }\end{array}$ \\
\hline Technical skills i.e., support & Digital transformation & Vendor partnership & Subjective norms \\
and knowledge & Top management & Government & Awareness \\
sechnology readiness & support & Trust \\
Security and privacy & Funding availability & Competitive pressure & Resistance to change \\
concerns & Organization readiness & & Perceived \\
Information quality & Industry investment & & \\
Task complexity & & & \\
Perceived behavioral control & & & \\
Cost effectiveness & & & \\
\hline
\end{tabular}




\section{Empirical Sector Argumentation}

Nowadays, the global AI market is worth $\$ 15$ billion with the expectation of reaching $\$ 72.5$ billion by 2025 . Over the past decade, AI research has led to significant advances in various sectors, ranging from machine translation to decision making in all fields, including intelligencepowered applications, voice assistants, chatbots, traffic control radars, etc.

Morocco, diagnosed in 2018 as a country in the data engineering phase, an important step before the implementation of an AI system, has put in place a general budget of 57M dollars in recent years. This covers a total of 7 transactions related to AI, ranking it second to the last in the MEA region although the outlook is positive in this field.

The promising sectors in AI in Morocco are: the agricultural sector, the banking sector, and the chemical industry. To choose an empirical field of study, a comparative study was conducted between these 3 sectors in Morocco and abroad based on what exists in the literature. No fieldwork was conducted.

\section{The Agricultural Sector}

The agricultural sector constitutes for Morocco one of the most important sectors having an incontestable economic and social importance. It represents a proportion approximately around 38\% in the total employment at the national level, of which $24.2 \%$ are agricultural and fishing workers and laborers. In rural areas, the sector accounts for $74 \%$ of total employment.

This activity contributes by $13 \%$ to the Gross Domestic Product with a variable margin according to territories. For some regions, it accounts as a dominant part of economic activity. In 2019, the country suffered a decrease of $5.8 \%$ in the volume of value added of agricultural activity against an increase of $3.7 \%$ in 2018 . Also, the agricultural activities have been down by $5 \%$ in the 1st quarter of 2020 (based on year 2007). Moreover, the value added at current prices in the 1st quarter of 2020 was 28.295M MAD against 29.797M MAD during the same period in 2019.

These variations in indicators are mainly due to climatic uncertainty and the management of rare resources such as water. This capital resource alerts the country, suffering from alarming water stress, as it is one of the regions most affected by global warming.

To confront the problems related to the agricultural sector, Morocco has put in place several strategies including sustainable agriculture based on energy efficiency and data exploitation. Towards the end of 2019 and the beginning of 2020, it began to use various tools that allow it to collect data, which was the first essential step in feeding artificial intelligence algorithms. Other actions have been put in place to facilitate the field of access to AI such as: 
- The agreement signed in 2018 between the African Union and the European Commission's Copernicus program. Hence, this allows African scientists to have access to free satellite data in order to predict weather conditions.

- The INRA-SOWIT partnership signed in June 2020 to provide African farmers with decision-support tools according to the location of their fields, the type of crop to recommend, the technical itinerary to adopt, and the appropriate agricultural advice. Hence, this can be achieved using digital technology and advanced technological tools such as unmanned aerial vehicles (UAVs).

- The launch of the first cereal treatment by drone in Morocco in December 2019 on the Sidi Kacem region.

- The introduction of the OCP's @tmar mobile application for agricultural advice based on artificial intelligence.

- Essaouira Innovation Lab and "Agri Edge" selected 10 farmers in June 2020 to benefit from the new program to equip farms with precision irrigation devices (sensors) to support the agricultural sector in the region. The country expects that in the short term, the digital should concern various areas of Moroccan agriculture through a multitude of tools including, the UAV farmer to map plots and measure water needs, the connected tractor, the probes to measure temperature, rainfall and humidity, as well as the connected barn such as automatic milking machines, supply of adapted food ration, etc.

At the global level, agriculture faces several challenges including the increasing scarcity of natural resources and the effects of climate change such as higher temperatures, variable rainfall, and the high frequency of extreme weather conditions like floods and droughts. To meet these challenges, the adoption of data-driven precision agriculture remains the only solution. Indeed, the use of data and AI tools offer several advantages to agriculture, namely:

- Achieving food safety through predictions via applications;

- Predict yields and control pests and diseases;

- Increase returns and reduce losses;

- Reduce the cost of field monitoring and accelerate response to crop threats;

- Consider new hydroponic crops for plants that grow only on the ground; and

- Access to financing and insurance.

Several countries have already started to exploit this type of agriculture. The share of AI in the agricultural market in 2018 was estimated globally at 545 million Euros and is expected to reach 2.4 billion in 2025. Since the 
beginning of 2020, the volume of investment in start-ups in the field of agricultural robot development has increased by $40 \%$ compared to the same period of the previous year and has already exceeded $\$ 600$ million.

Numerous countries are using IBM's WATSON business intelligence platform, which combines predictive analysis, AI, weather data, and IoT sensors to provide farmers with information on tillage, planting, spraying, and harvesting. In addition, Microsoft's AI for earth program has awarded 110 grants to 27 countries, not to mention the $\$ 800$ million raised worldwide to fund AgriTech start-ups.

In other African countries, the use of AI data and tools in agriculture has become frequent. In Kenya, Nuru software is being used to diagnose cassava diseases, identify fall armyworm infestations in maize, predict crop growth and productivity, and protect vital food commodities from rising temperatures. Also, the AGIN mobile service connects Kenyan farmers to credit services by providing them with a credit profile based on the size, location, soil composition and crops on the farm. In Cameroon, farmers can scan, using applications of the company Agrix Tec, a sheet of the infected crop so that the AI algorithm can analyze it and recommend the appropriate treatment.

\section{The Banking Sector}

The banking system is one of the most important systems for the economic growth of a country; its profitability allows for the management of funds for development financing. A well-functioning banking system will lead to accelerated accumulation of both physical and human capital, boost innovation in technology, and thus create the conditions for economic growth and poverty reduction.

Morocco has a total of 86 credit and related institutions, 24 of them are banks. Five of these 24 are participatory banks and six are traded on the financial markets. The bank penetration rate in June 2019 reached $78 \%$ against $76 \%$ in December 2018, with 6412 bank counters, making an average of one counter for about 5500 inhabitants. The net banking income in June 2019 was 26.1 billion MAD while the net result was 7.6 billion MAD.

Banks around the world promote the use of artificial intelligence for the following reasons:

- Thanks to AI, the bank can predict a customer's future situation, thus allowing it to offer more targeted and personalized services based on their consumption practices;

- By using virtual assistants, customer complaints and questions can be handled 24/7;

- Algorithms can be modeled to identify customers who are likely to leave the bank or those at risk of over-indebtedness in order to accompany 
them, to perform semantic processing of e-mails by prioritizing urgent requests, or even to promote strong regulatory compliance.

At the national level, the use of AI is not yet fully effective. Thus, some banks are trying to see the result by launching a chatbot market test, testing anti-fraud systems based on AI, but in general the banks in Morocco are still in the phase of automation and Fintech.

At the international level, chatbots represent about $13.5 \%$ of the AI providers' offer in the American banking sector: oriented functions $25 \%$ and risk management functions 56\%. In France, banks cite AI as a technology that is probably $40 \%$ capable of being implemented in the next 12 months.

\section{The Chemical Industry Sector}

The industrial sector in Morocco encompasses 12 industries: automotive, aeronautics, textiles, leather, electronics, electrical, building materials, renewable energy, mechanical and metallurgical, chemical, pharmaceutical, and offshoring.

Between 2014 and 2019, this sector employed a total of 504954 people. 165000 jobs were created in the textile industry which generates for Morocco about 34.2 million MAD of export turnover, and this is followed by 116000 jobs in the automotive industry with $+60 \%$ of local integration. The latter remains the first exporting sector with 72 billion MAD of export turnover.

In the chemical industry, the statistics are highly important and the turnover is worth 21 billion MAD. The value added exceeds 3.3 billion MAD and employs 15,500 people. Furthermore, the sector is a central player that supplies the raw materials for a large number of products. This sector benefits from the presence of OCP, leader in phosphate chemistry, whose activities represent $52 \%$ of the sector's turnover, $90 \%$ of exports, $67 \%$ of investments, and $22 \%$ of jobs.

The use of AI in the chemical industry covers various steps from modeling to diagnosis, optimization, process control, and fault detection. This would allow companies to estimate optimal parameters such as scale functions, universes of discourse, and membership functions so as to remove duplicative, wasteful or confusing rules. It would also help to optimize nonlinear and complex chemical processes through generic population-based metaheuristic optimization algorithms so as to minimize operation and production costs or maximize energy efficiency, yields, productivity, profitability, safety, and reliability of the process. As far as control is concerned, neural networks can be used in different process areas such as thermal processes, reaction processes, separation and purification, etc.

In Morocco, the chemical industry is at the forefront of industries to better implement this technology because it uses very precise quantities at 
appropriate temperatures and pressure levels. The OCP group has started the implementation of big data infrastructure to collect data. In order to move to the next stage of AI, it launched the Benguerir Data Center in 2020 and is setting up a system to predict the demand for phosphate fertilizers in Africa based on big data and new technologies such as IoT and AI. Thus, this is aimed at forecasting consumption and anticipating fluctuations in demand.

Globally, this industry accounted for $\$ 4$ trillion of sales in 2017, 19\% of which were exported. However, the major challenge for producers is the customs duties imposed on chemical products, which negatively impact trade flows. This has prompted them to think about setting up an autonomous selflearning system which they believe is capable of summarizing previous incidents and anticipating new ones. This will enable any company to accurately monitor purchasing behaviors and prices in the markets and at customers' sites in order to adapt when necessary. Also, Total French oil and gas group had signed a partnership agreement in 2018 with Google in the field of AI. This is applied to the analysis of subsoil data in order to facilitate the exploration and production of oil and gas. Consequently, this means specialized companies use AI and IoT for the manufacture of autonomous devices for oil wells, simulation of deposits, oil and gas recovery and production, etc.

\section{Research Synthesis}

Based on the analysis made at the level of the 3 sectors, it is noticeable that the banking sector cannot be chosen because of the lack of vision and the lack of information. More so, the field in the banking sector is not yet mature to adopt AI and big data tools. Banks are still in the phase of automation and fintech. Also, access to information in banks remains the major issue because some actors have the information that others do not have due to the theory of information asymmetry.

In contrast, the two sectors of agriculture and chemical industry are fertile grounds for the study because the initiatives have already been launched, and the strategy for the deployment of these tools is clear and validated. The issue at stake lies in access to information because these sectors are predominantly owned by large groups. It was important to keep both sectors for the moment. Thereafter, one of the sectors will be selected based on the information accessibility in the fieldwork and there is a comparative study between the two sectors.

To this end, the definition of the study problem has been successfully done. Thus the central research question remains the following:

What are the variables of the intention of adoption and acceptance of the artificial intelligence and big data tools among the leaders of the organizations of the agricultural and chemical industrial sectors in Morocco? 
From this central question, other sub-questions were derived as shown below:

- What are the technological and organizational variables that impact the adoption of AI and big data in these organizations?

- What are the behavioral variables that have a positive or negative effect on the acceptance of these two technologies among the leaders of companies in both sectors?

- Can the digital transformation be considered as a determinant variable of AI and big data adoption?

\section{Conclusion}

In conclusion, the purpose of this study can be summarized in the definition of the research problem and the choice of an empirical sector. Hence, the interest of this research project remains the understanding of the phenomenon of the adoption and acceptance of artificial intelligence and big data within organizations in Morocco and the detection of the variables that occur during this process. This is done in order to positively act upon them and succeed in the adoption and acceptance phase.

Furthermore, it is important to note that this study was carried out within the context of preparing a doctoral thesis entitled: "Analysis of variables of the intention of adoption and acceptance of artificial intelligence and big data tools among the leaders of organizations in Morocco". Therefore, the next article will focus on developing a theoretical model that will be followed by exploratory and confirmatory studies.

\section{Acknowledgement}

This work is carried out with the support of the National Center for Scientific and Technical Research in Morocco (CNRST) within the program of Research Excellence Grants.

\section{References:}

1. Adnan, N., Nordin, S., Bahruddin, M. A. bin, \& Ali, M. (2018). How trust can drive forward the user acceptance to the technology? Invehicle technology for autonomous vehicle. https://doi.org/10.1016/J.TRA.2018.10.019

2. Alhashmi, S. F. S., Alshurideh, M., Kurdi, B. A., \& Salloum, S. (2020). A Systematic Review of the Factors Affecting the Artificial Intelligence Implementation in the Health Care Sector. AICV. https://doi.org/10.1007/978-3-030-44289-7_4

3. Alsheiabni, S., Cheung, Y., \& Messom, C. (2019). Factors inhibiting the adoption of artificial intelligence at organizational-level: A preliminary investigation. AMCIS 2019 Proceedings, 2. 
https://research.monash.edu/en/publications/factors-inhibiting-theadoption-of-artificial-intelligence-at-org

4. Baig, M., Shuib, L., \& Yadegaridehkordi, E. (2019). Big data adoption: State of the art and research challenges. Inf. Process. Manag. https://doi.org/10.1016/J.IPM.2019.102095

5. Belanche, D., Casaló, L. V., \& Flavián, C. (2019). Artificial Intelligence in FinTech: Understanding robo-advisors adoption among customers. Industrial Management \&amp; Data Systems, 119(7), 1411.

6. Canhoto, A. I., \& Clear, F. (2020). Artificial intelligence and machine learning as business tools: A framework for diagnosing value destruction potential. Business Horizons, 63(2), 183-193.

7. Chafik, K. (2021). Regards sur la recherche en systèmes d'information des organisations: Cas du Maroc.

8. Chafik, K., \& Abbassi, A. E. (2013). The decision to invest in information systems: Case of adopting ERP in the Moroccan Public largest companies". 14.

9. Chafik, K., \& Bannaceur, A. (2015). Les déterminants de l’intention d'adoption du commerce électronique chez les dirigeants-propriétaires des P.M.E. marocaines: Test des variables d'extension du modèle TAM.https://www.academia.edu/30419601/Les_d\%C3\%A9terminan ts_de_lintention_dadoption_du_commerce_\%C3\%A9lectronique_ch ez_les_dirigeants_propri\%C3\%A9taires_des_P_M_E_marocaines_T est_des_variables_dextension_du_mod\%C3\%A8le_TAM

10. Chan-Olmsted, S. M. (2019). A Review of Artificial Intelligence Adoptions in the Media Industry. https://doi.org/10.1080/14241277.2019.1695619

11. Chatterjee, S., \& Bhattacharjee, K. K. (2020). Adoption of Artificial Intelligence in Higher Education: A Quantitative Analysis Using Structural Equation Modelling. Education and Information Technologies, 25(5), 3443-3463. https://doi.org/10.1007/s10639-02010159-7

12. Chen, H. (2019). Success Factors Impacting Artificial Intelligence Adoption-Perspective From the Telecom Industry in China. Theses and Dissertations in Business Administration. https://doi.org/10.25777/a8q8-gm13

13. Crevier, D. (1994). The Tumultuous History of the Search for Artificial Intelligence,. 1993. Basic Books, New York, NY. 432 pages. ISBN: 0-465-02997-3. \$27.50, 1994.

https://journals.sagepub.com/doi/abs/10.1177/027046769401400414

14. Cruz-Benito, J., Sánchez-Prieto, J. C., Therón, R., \& García-Peñalvo, F. J. (2019). Measuring Students' Acceptance to AI-Driven 
Assessment in eLearning: Proposing a First TAM-Based Research Model. In P. Zaphiris \& A. Ioannou (Eds.), Learning and Collaboration Technologies. Designing Learning Experiences (pp. 15-25). Springer International Publishing. https://doi.org/10.1007/978-3-030-21814-0_2

15. Dejoux, C. (2018). Transformation numérique et intelligence artificielle: Deux révolutions à ne pas rater pour les entreprises. The Conversation. http://theconversation.com/transformation-numeriqueet-intelligence-artificielle-deux-revolutions-a-ne-pas-rater-pour-lesentreprises-96598

16. Demchenko, Y., Grosso, P., Laat, C., \& Membrey, P. (2013). Addressing big data issues in Scientific Data Infrastructure. 2013 International Conference on Collaboration Technologies and Systems (CTS). https://doi.org/10.1109/CTS.2013.6567203

17. DEPF Etudes. (2019). Le secteur agricole marocain: Tendances structurelles, enjeux et perspectives de développement. http://depf.finances.gov.ma/etudes-et-publications/

18. Diao, M. (2018). Robotisation/Intelligence Artificielle: Ce que les banques y gagnent. http://fnh.ma. https://fnh.ma/article/-/robotisationintelligence-artificielle-ce-que-les-banques-y-gagnent

19. Du, H., Zhu, G., \& Zheng, J. (2021). Why travelers trust and accept self-driving cars: An empirical study. Travel Behaviour and Society, 22(0). https://trid.trb.org/view/1729795

20. Duan, Y., Edwards, J. S., \& Dwivedi, Y. K. (2019). Artificial intelligence for decision making in the era of Big Data - evolution, challenges and research agenda. International Journal of Information Management, 48, 63-71.

https://doi.org/10.1016/j.ijinfomgt.2019.01.021

21. Ducrey, V., \& Vivier, E. (2019). Le guide de la transformation digitale: La méthode en 6 chantiers pour réussir votre transformation! EYROLLES.

22. Dwivedi, Y. K., Hughes, L., Ismagilova, E., Aarts, G., Coombs, C., Crick, T., Duan, Y., Dwivedi, R., Edwards, J., Eirug, A., Galanos, V., Ilavarasan, P. V., Janssen, M., Jones, P., Kar, A. K., Kizgin, H., Kronemann, B., Lal, B., Lucini, B., ... Williams, M. D. (2021). Artificial Intelligence (AI): Multidisciplinary Perspectives on Emerging Challenges, Opportunities, and Agenda for Research, Practice and Policy. International Journal of Information Management, 57, 101994. https://doi.org/10.1016/j.ijinfomgt.2019.08.002

23. European center for digital competitiveness - ESCP Business School (2020). Digital riser report 2020. Retrieved from digital 
competitiveness:

https://digital-competitiveness.eu/wpcontent/uploads/ESCP03_Digital-Riser-Ranking_2020-09-14-1.pdf

24. Faggella, D. (2020). AI in Banking-An Analysis of America's 7 Top Banks. Emerj. https://emerj.com/ai-sector-overviews/ai-in-bankinganalysis/

25. Fan, W., Liu, J., Zhu, S., \& Pardalos, P. M. (2020). Investigating the impacting factors for the healthcare professionals to adopt artificial intelligence-based medical diagnosis support system (AIMDSS). Annals of Operations Research, 294(1), 567-592.

26. Fernandes, T., \& Oliveira, E. (2021). Understanding consumers' acceptance of automated technologies in service encounters: Drivers of digital voice assistants adoption. Journal of Business Research, 122, 180-191. https://doi.org/10.1016/j.jbusres.2020.08.058

27. Garrier, C. (1991). Maîtrise de l'intelligence artificielle. Marabout.

28. Gursoy, D., Chi, O. H., Lu, L., \& Nunkoo, R. (2019). Consumers Acceptance of Artificially Intelligent (AI) Device Use in Service Delivery. International Journal of Information Management, 49, 157169. https://doi.org/10.1016/j.ijinfomgt.2019.03.008

29. Harbouze, R., Pellissier, J.-P., Rolland, J.-P., \& Khechimi, W. (2019). Rapport de synthèse sur l'agriculture au Maroc (p. 104) [Research Report]. CIHEAM-IAMM. https://hal.archives-ouvertes.fr/hal02137637

30. Henriette, E., Feki, M., \& Boughzala, I. (2016). Digital transformation challenges. MCIS 2016: 10th Mediterranean Conference on Information Systems, . https://hal.archives-ouvertes.fr/hal-01413172

31. Horacio (2020, January 13). How Will Artificial Intelligence Change The Banking Industry? Fintech News. https://www.fintechnews.org/how-will-artificial-intelligence-changethe-banking-idustry/

32. Jha, K., Doshi, A., Patel, P., \& Shah, M. (2019). A comprehensive review on automation in agriculture using artificial intelligence. Artificial Intelligence in Agriculture, 2, 1-12. https://doi.org/10.1016/j.aiia.2019.05.004

33. Kakkar, S. (2017). A Study on Artificial Intelligence in E-commerce. International Journal of Advances in Engineering \& Scientific Research, 4(4), 62-68. https://doi.org/10.5281/zenodo.1123241

34. Kazakçi, A. (2017). Transformation digitale, par l'intelligence artificielle et la valorisation des données. Knowledge@Wharton. https://hal.archives-ouvertes.fr/hal-01791196

35. Kedra, J., \& Gossec, L. (2020). Big Data and artificial intelligence: Will they change our practice? Joint Bone Spine, 87(2), 107-109. https://doi.org/10.1016/j.jbspin.2019.09.001 
36. Kencebay, B. (2019). User acceptance of driverless vehicles and robots with aspect of personal economy. Journal of Transnational Management, 24(4), 283-304. https://doi.org/10.1080/15475778.2019.1664234

37. Kervenoael, R. de, Hasan, R., Schwob, A., \& Goh, E. (2020). Leveraging human-robot interaction in hospitality services: Incorporating the role of perceived value, empathy, and information sharing into visitors' intentions to use social robots. Tourism Management, 78 , 104042. https://doi.org/10.1016/j.tourman.2019.104042

38. Kim, S., \& Kim, B. (2020). A Decision-Making Model for Adopting Al-Generated News Articles: Preliminary Results. Sustainability, 12(18), 7418. https://doi.org/10.3390/su12187418

39. Lee, V.-H., Hew, J.-J., Leong, L.-Y., Tan, G. W.-H., \& Ooi, K.-B. (2020). Wearable payment: A deep learning-based dual-stage SEMANN analysis. Expert Systems with Applications, 157, 113477. https://doi.org/10.1016/j.eswa.2020.113477

40. Les bénéfices de l'IA sur l'agriculture. (2018). In Microsoft experiences. https://experiences.microsoft.fr/articles/intelligenceartificielle/ia-agriculture/

41. Les Secteurs Industriels. (n.d.). Ministere de I'lndustrie, du Commerce et de I'Economie Verte et Numerique. Retrieved July 18, 2021, from http://www.mcinet.gov.ma/fr/content/les-secteurs-industriels

42. Maaroufi, Y. (2020). Note d'information relative à la situation de l'économie nationale en 2020 et ses perspectives d'évolution en 2021 (Note de synthèse du budget économique exploratoire 2021). Site institutionnel du Haut-Commissariat au Plan du Royaume du Maroc. https://www.hcp.ma/Note-d-information-relative-a-la-situation-de-leconomie-nationale-en-2020-et-ses-perspectives-d-evolution-en2021-Note_a2568.html

43. Mahroof, K. (2018). A human-centric perspective exploring the readiness towards smart warehousing: The case of a large retail distribution warehouse. International Journal of Information Management, 45 , 176-190. https://doi.org/10.1016/j.ijinfomgt.2018.11.008

44. McCorduck, P. (2004). Machines Who Think (2nd edition). Routledge.

45. Microsoft, E. C. (2019). Artificial intelligence in the Middle East and Africa: prospects for 2019 and beyond. LLC's report.

46. Ministry of Agriculture and Maritime Fisheries; World Bank (May 2011); reports on Green Morocco Plan, Framework Analysis of Social 
and Poverty Impacts and Implementation Risks. Retrieved from the portal of the High Commission for Planning, :

http://www.agriculture.gov.ma

47. Moor, J. (2006). The Dartmouth College Artificial Intelligence Conference: The Next Fifty Years. AI Magazine, 27(4), 87-87. https://doi.org/10.1609/aimag.v27i4.1911

48. Osuolale, A. F., Adewale, O. S., \& Abimbola, O. J. (2017). Schematic Structure of National Data Harmonization System for Identity Management. European Scientific Journal, ESJ, 13(3), 318-318. https://doi.org/10.19044/esj.2017.v13n3p318

49. Patil, K., \& Kulkarni, M. S. (2019). Artificial Intelligence in Financial Services: Customer Chatbot Advisor Adoption. 9(1), 8.

50. Pillai, R., \& Sivathanu, B. (2020). Adoption of artificial intelligence (AI) for talent acquisition in IT/ITeS organizations. https://doi.org/10.1108/bij-04-2020-0186

51. Pillai, R., Sivathanu, B., \& Dwivedi, Y. (2020). Shopping intention at AI-powered automated retail stores (AIPARS). Journal of Retailing and Consumer Services, 57, 102207. https://doi.org/10.1016/j.jretconser.2020.102207

52. Quan, X., \& Sanderson, J. (2018). Understanding the Artificial Intelligence Business Ecosystem. IEEE Engineering Management Review. https://doi.org/10.1109/EMR.2018.2882430

53. Russell, S. J., \& Norvig, P. (2002). Artificial Intelligence: A Modern Approach (2nd edition). Prentice Hall.

54. Saggi, M. K., \& Jain, S. (2018). A survey towards an integration of big data analytics to big insights for value-creation. Information $\begin{array}{llll}\text { Processing \& } \quad \text { Management, 54(5), } & \text { 758-790. }\end{array}$ https://doi.org/10.1016/j.ipm.2018.01.010

55. Salloum, S., Alattar, S., \& Abdallah, S. (2019, October 2). Critical Success Factors for Implementing Artificial Intelligence (AI) Projects in Dubai Government United Arab Emirates (UAE) Health Sector: Applying the Extended Technology Acceptance Model (TAM). https://doi.org/10.1007/978-3-030-31129-2_36

56. Sánchez-Prieto, J. C., Cruz-Benito, J., Therón, R., \& García-Peñalvo, F. J. (2019). How to Measure Teachers' Acceptance of AI-driven Assessment in eLearning: A TAM-based Proposal. Proceedings of the Seventh International Conference on Technological Ecosystems for Enhancing Multiculturality, 181-186. https://doi.org/10.1145/3362789.3362918

57. Shibly, H. A. (2020). Investigating the Effectiveness of Business Intelligence Systems A PLS-SEM Approach. https://doi.org/10.5281/zenodo.4978963 
58. Tableau de bord du système bancaire-Juin 2020. (2020). BANK ALMAGHRIB. http://www.bkam.ma/Supervision-bancaire/Indicateurset-publications/Tableau-de-bord-du-systeme-bancaire/Tableau-debord-du-systeme-bancaire-juin-2020

59. Technologie numérique-Comment l'intelligence artificielle transforme l'agriculture. (2019).

https://spore.cta.int/fr/issue/technologie-numerique-comment-lintelligence-artificielle-transforme-l-agriculture-sid0291dc264-f19f4418-9738-fa6f42b7f3aa

60. Ullah, F., Sepasgozar, S. M. E., \& Wang, C. (2018). A Systematic Review of Smart Real Estate Technology: Drivers of, and Barriers to, the Use of Digital Disruptive Technologies and Online Platforms. Sustainability, 10(9), 3142. https://doi.org/10.3390/su10093142

61. Vijai, C. (2018). Artificial Intelligence in Indian Banking Sector: Challenges and Opportunities. International Journal of Advanced Research, 7(4), 1581.

62. Weber, F. A., \& Schütte, R. (2019). State-of-the-art and adoption of artificial intelligence in retailing. https://doi.org/10.1108/DPRG-092018-0050

63. Ye, T., Xue, J., He, M., Gu, J., Lin, H., Xu, B., \& Cheng, Y. (2019). Psychosocial Factors Affecting Artificial Intelligence Adoption in Health Care in China: Cross-Sectional Study. Journal of Medical Internet Research, 21(10), e14316. https://doi.org/10.2196/14316

64. Yu, K., \& Huang, G. (2020). Exploring consumers' intent to use smart libraries with technology acceptance model. Electron. Libr. https://doi.org/10.1108/el-08-2019-0188 